Revista Eletrônica de Direito Processual - REDP.

Rio de Janeiro. Ano 13. Volume 20. Número 1. Janeiro a Abril de 2019

Periódico Quadrimestral da Pós-Graduação Stricto Sensu em Direito Processual da UERJ

Patrono: José Carlos Barbosa Moreira (in mem.). ISSN 1982-7636. pp. 82-107 www.redp.uerj.br

\title{
O DIREITO FUNDAMENTAL DE ACESSO À JUSTIÇA E A EFETIVIDADE DA MEDIAÇÃO NAS CAUSAS DE FAMÍLIA NO CEJUSC EM UBERLÂNDIA NO PERÍODO DE JULHO/2016 A MAIO/2018 1
}

\author{
THE FUNDAMENTAL RIGHT OF ACCESS TO JUSTICE AND THE \\ EFFECTIVENESS OF MEDIATION IN FAMILY CAUSES IN UBERLÂNDIA \\ CEJUSC, IN THE PERIOD OF JULY/ 2016 TO MAY/2018
}

Carlos José Cordeiro Doutor e Mestre em Direito pela Pontifícia Universidade Católica de São Paulo (PUC/SP). Especialista pela Escola Superior da Magistratura do Mato Grosso do Sul. Professor efetivo da Universidade Federal de Uberlândia/MG (UFU). Juiz de direito - Tribunal de Justiça de Minas Gerais (TJMG). Uberlândia, Minas Gerais, Brasil. E-mail: carlosjcordeiro@terra.com.br

Laura Borges Ricardo Mestranda do Programa de Pós-Graduação em Direito, da Universidade Federal de Uberlândia (UFU). Especialista em Direito Processual Civil pela Universidade Potiguar (UNP) e em Direito das Relações Sociais pela Faculdade Católica de Uberlândia. Bacharela em Direito pela Universidade Federal de Uberlândia (UFU). Advogada e professora da Faculdade UNA de Uberlândia. Uberlândia, Minas Gerais, Brasil. E-mail: laura.borges.r@hotmail.com

RESUMO: O artigo consiste na análise do direito fundamental de acesso à justiça e a efetividade da mediação familiar, no CEJUSC de Uberlândia, no período de julho/2016 a maio/2018. Sendo assim, pretende-se investigar a seguinte problemática: Este órgão é eficiente no acesso à justiça, através da mediação familiar? Demonstra-se pelos dados

\footnotetext{
${ }^{1}$ Artigo recebido em 02/10/2018 e aprovado em 30/03/2019.
} 
Revista Eletrônica de Direito Processual - REDP.

Rio de Janeiro. Ano 13. Volume 20. Número 1. Janeiro a Abril de 2019

Periódico Quadrimestral da Pós-Graduação Stricto Sensu em Direito Processual da UERJ

Patrono: José Carlos Barbosa Moreira (in mem.). ISSN 1982-7636. pp. 82-107

www.redp.uerj.br

estatísticos um aumento no número de acordos em mediações neste período, o que indica

que o direito fundamental ao acesso à justiça tem sido garantido. A pesquisa utiliza-se do método de abordagem indutivo, do procedimento estruturalista, funcionalista e estatístico e da técnica da documentação indireta e direta.

PALAVRAS-CHAVE: Mediação. Efetividade. Acesso à justiça. CEJUSC. Uberlândia.

ABSTRACT: The article consists of the analysis of the fundamental right of access to justice and the effectiveness of family mediation, in the CEJUSC of Uberlândia, from July 2016 to May 2018. Therefore, it is intended to investigate the following problem: Is this organ efficient in access to justice through family mediation? Statistical data show an increase in the number of agreements in mediations in this period, which indicates that the fundamental right to access to justice has been guaranteed. The research uses the method of inductive approach, structuralist, functionalist and statistical procedure and the technique of indirect and direct documentation.

KEYWORDS: Mediation. Effectiveness. Access to justice. CEJUSC. Uberlândia.

SUMÁRIO: 1 Introdução; 2 O direito fundamental de acesso à justiça; 3 A mediação familiar e suas dimensões pré-processual e processual; 4 CEJUSC: diretrizes e organização; 5 CEJUSC em Uberlândia: estrutura e funcionamento; 6 A efetividade da mediação familiar no CEJUSC em Uberlândia; Conclusão; Referências Bibliográficas.

\section{INTRODUÇÃO}

A Resolução $n^{\circ}$ 125/2010², do Conselho Nacional de Justiça, instituiu, no Brasil, política pública de tratamento adequado dos conflitos jurídicos, com claro estímulo à solução por autocomposição. Seguindo esta orientação, o Poder Legislativo editou várias

\footnotetext{
2 BRASIL. Resolução $n^{\circ}$ 125, de 29/11/2010. Dispõe sobre a Política Judiciária Nacional de tratamento adequado dos conflitos de interesses no âmbito do Poder Judiciário e dá outras providências. Brasília, Conselho Nacional de Justiça, 29 de novembro de 2010.
} 
Revista Eletrônica de Direito Processual - REDP.

Rio de Janeiro. Ano 13. Volume 20. Número 1. Janeiro a Abril de 2019

Periódico Quadrimestral da Pós-Graduação Stricto Sensu em Direito Processual da UERJ

Patrono: José Carlos Barbosa Moreira (in mem.). ISSN 1982-7636. pp. 82-107

www.redp.uerj.br

leis, inclusive o novo Código de Processo $\mathrm{Civil}^{3}$, que expressa, em seu art. $3^{\circ}, \S 3^{\circ}$, que a mediação e outros métodos de solução consensual de conflitos deverão ser estimulados por juízes, defensores públicos, membros do Ministério Público, advogados, inclusive no curso do processo judicial.

Para viabilizar esta política pública, estabeleceu-se uma estrutura organizacional chefiada pelo Conselho Nacional de Justiça, cuja incumbência é formular o programa com o objetivo de promover ações de incentivo à autocomposição de litígios e à pacificação social.

Dentro dessa estrutura, encontram-se os Centros Judiciários de Solução de Conflitos (CEJUSCs), criados pelos Tribunais, e que constituem unidades do Poder Judiciário com o objetivo primordial de realizar as sessões de conciliação e mediação do tribunal.

Sendo assim, o presente trabalho se dedica a analisar a seguinte problemática: $\mathrm{O}$ CEJUSC de Uberlândia é eficiente no acesso à justiça, através da mediação familiar?

O presente estudo defende que o CEJUSC de Uberlândia tem garantido aos cidadãos o direito fundamental ao acesso à justiça, através da mediação familiar. $\mathrm{O}$ objetivo geral consiste em apresentar a estrutura e funcionamento do CEJUSC em Uberlândia no período de julho/2016 a maio/2018.

Para tal objetivo, faz-se uma análise do movimento mundial de Acesso à Justiça e o Projeto Florença, apresenta-se e interpreta-se os dados dos pré-processos e processos fornecidos pelo CEJUSC/Uberlândia, a fim de verificar a efetividade da mediação no acesso à justiça.

A pesquisa foi desenvolvida a partir do método de abordagem indutivo a partir da observação da estrutura, funcionamento e atuação do CEJUSC, assim como dos elementos oferecidos pelos seus membros para a construção de interpretações acerca de seu papel no acesso à justiça através da mediação.

Os métodos de procedimento utilizados são o estruturalista, funcionalista e estatístico $^{4}$. O método de procedimento estruturalista é utilizado na análise da estrutura e

\footnotetext{
${ }^{3}$ BRASIL. Novo Código de Processo Civil. In: CÉSPEDES, Lívia (Org.). Vade Mecum Saraiva. 23 ed. atual. e ampl. São Paulo: Saraiva, 2017. p. 366-488.

${ }^{4}$ LAKATOS, Eva Maria; MARCONI, Marina de Andrade. Fundamentos de Metodologia científica. 5. ed. São Paulo: Atlas, 2003.
} 
Revista Eletrônica de Direito Processual - REDP.

Rio de Janeiro. Ano 13. Volume 20. Número 1. Janeiro a Abril de 2019

Periódico Quadrimestral da Pós-Graduação Stricto Sensu em Direito Processual da UERJ

Patrono: José Carlos Barbosa Moreira (in mem.). ISSN 1982-7636. pp. 82-107

www.redp.uerj.br

funcionamento do CEJUSC em nível abstrato e concreto para dar suporte na verificação da efetivação do direito fundamental de acesso à justiça. $\mathrm{O}$ método funcionalista é de suma importância para a pesquisa na medida em que propicia uma interpretação coerente da função do CEJUSC na mediação, nas causas de família. Já o método estatístico baseia-se na utilização da teoria das estatísticas das probabilidades.

Para realizar todos esses passos, a pesquisa utiliza-se da técnica da documentação indireta, através da pesquisa bibliográfica e doutrinária acerca dos conceitos teóricos e os paradigmas que fundamentam o Direito Fundamental de acesso à justiça e a técnica da documentação direta por meio da observação direta intensiva com a técnica da observação sistemática e entrevista padronizada.

\section{O DIREITO FUNDAMENTAL DE ACESSO À JUSTIÇA}

O termo acesso à justiça comporta diversas interpretações e abordagens, seja em relação ao sentido social do direito, ao se tratar da justiça, ou no sentido de um discurso técnico voltado para o instrumentalismo do processo.

Mas qual é a Justiça que se espera obter do Poder Judiciário? É fato que a questão da justiça constitui um tema clássico da teoria do direito que tem atravessado os séculos, sem que se chegue a um consenso. Aristóteles expõe que a Justiça significa a virtude que nos leva a desejar o que é justo ${ }^{5}$. John Rawls, principal expoente da perspectiva liberal, apregoa que justiça é a igualdade e que a desigualdade só se justifica se houver vantagens aos desiguais ${ }^{6}$. A acepção mais conhecida do termo justiça é atribuída a Ulpiano, que conceitua a justiça como a vontade de dar a cada um o que é seu ${ }^{7}$.

A expressão acesso à Justiça, de acordo com Cappelleti e Garth ${ }^{8}$, é de difícil definição, mas determina "[...] o sistema pelo qual as pessoas podem reivindicar seus direitos e/ou resolver seus litígios sob os auspícios do Estado". Dessa forma, primeiramente, o sistema deve ser igualmente acessível a todos e produzir resultados que sejam individual e socialmente justos. Esses autores, em meados de 1965, iniciaram o

\footnotetext{
${ }^{5}$ ARISTÓTELES. Ética a Nicômaco. São Paulo: Editora Atlas S. A, 2009.

${ }^{6}$ LOVETT, Frank. Uma teoria da justiça, de John Rawls [recurso eletrônico]. Porto Alegre: Penso, 2013.

${ }^{7}$ NADER, Paulo. Introdução ao estudo do direito. 40. ed. rev. e atual. Rio de Janeiro: Forense, 2017.

${ }^{8}$ CAPPELLETTI, Mauro; GARTH, Bryant. Tradução de Ellen Gracie Northfleet. Acesso à Justiça. Porto Alegre: Fabris, 2002, p. 8.
} 
Revista Eletrônica de Direito Processual - REDP.

Rio de Janeiro. Ano 13. Volume 20. Número 1. Janeiro a Abril de 2019

Periódico Quadrimestral da Pós-Graduação Stricto Sensu em Direito Processual da UERJ

Patrono: José Carlos Barbosa Moreira (in mem.). ISSN 1982-7636. pp. 82-107

www.redp.uerj.br

Projeto Florença, promovido pela fundação Ford, o que resultou no movimento mundial de

Acesso à Justiça. As soluções encontradas foram dispostas nas ondas de acesso à justiça, cujo principal objetivo é a identificação de entraves ao acesso e que resultou em críticas a concepção formalista e dogmática do direito e da perspectiva unidimensional da Justiça como aplicadora das disposições legais.

A primeira onda desse movimento é a assistência judiciária aos mais carentes, que objetiva proporcionar serviços jurídicos a estes, para se evitar o obstáculo econômico de acesso à justiça, seja por meio da assistência judiciária, antes do início da ação, com a concretização dos direitos e a orientação dos envolvidos e, também durante o processo, com o patrocínio para a ação e a defesa dos direitos, por meio da Defensoria Pública, da isenção dos honorários advocatícios e das demais custas processuais.

A segunda onda preocupa-se com a representação em Juízo dos interesses difusos e coletivos e tem como finalidade contornar o obstáculo organizacional do acesso à justiça. A combinação de ações coletivas, as sociedades de advogados do interesse público, a assessoria pública e o advogado público podem auxiliar a superar esta questão e conduzir à reivindicação eficiente dos interesses difusos.

E a terceira onda centra sua atenção no conjunto geral de instituições e mecanismos, pessoas e procedimentos utilizados para processar e prevenir conflitos nas sociedades modernas. É o enfoque do acesso à justiça, que engloba alterações nas formas de procedimento, mudanças na estrutura dos tribunais ou a criação de novos tribunais, o uso de pessoas leigas, modificações no direito substantivo destinadas a evitar litígios ou facilitar sua solução e a utilização de mecanismos privados ou informais de solução dos litígios. De acordo com Cappelletti e Garth": "O desafio é criar foros que sejam atraentes para os indivíduos, não apenas do ponto de vista econômico, mas também físico e psicológico, de modo que eles se sintam à vontade e confiantes [...]”"

Sendo os direitos fundamentais aqueles cujo objetivo é promover e proteger a dignidade da pessoa humana, sendo proposições jurídicas reconhecidas e protegidas na perspectiva do direito constitucional interno dos Estados, a Constituição Federal Brasileira $^{10}$, no art. $5^{\circ}, \mathrm{XXXV}$, dispõe sobre o direito fundamental de acesso à justiça,

\footnotetext{
${ }^{9}$ Ibid., p. 97.

${ }^{10}$ BRASIL. Constituição da República Federativa do Brasil. In: CÉSPEDES, Lívia (Org.). Vade Mecum Saraiva. 23 ed., atual. e ampl. São Paulo: Saraiva, 2017. p. 5- 126.
} 
Revista Eletrônica de Direito Processual - REDP.

Rio de Janeiro. Ano 13. Volume 20. Número 1. Janeiro a Abril de 2019

Periódico Quadrimestral da Pós-Graduação Stricto Sensu em Direito Processual da UERJ

Patrono: José Carlos Barbosa Moreira (in mem.). ISSN 1982-7636. pp. 82-107

www.redp.uerj.br

garantindo que a lei não excluirá da apreciação do Poder Judiciário lesão ou ameaça a direito. $\mathrm{O}$ art. $3^{\circ}$ do Código de Processo Civil repete semelhante disposição a título de norma fundamental do processo civil.

É crescente a ideia na doutrina e na jurisprudência no sentido de que as normas que regem o Direito Processual Civil devem consagrar a aplicação dos direitos e garantias fundamentais. A doutrina atual expõe que o processo civil se constitucionalizou, isto é, o processo deve ser examinado, estudado e compreendido à luz da Constituição. O modelo constitucional do processo nada mais é o resultado da interpretação das leis processuais a partir da necessidade de que o direito fundamental a um processo justo (tutela jurisdicional efetiva, célere e adequada) seja respeitado, consoante os princípios e garantias constitucionais processuais.

Humberto Theodoro Júnior ${ }^{11}$ define o acesso à justiça como "[...] o direito a uma tutela efetiva e justa para todos os interesses dos particulares agasalhados pelo ordenamento jurídico".

Ademais, de acordo com Marinoni, Mitidiero e Sarlet ${ }^{12}$, no direito fundamental ao acesso à justiça exige-se: “[...] que os procedimentos e a técnica processual sejam estruturados pelo legislador segundo necessidades do direito material e compreendidos pelo juiz de acordo com o modo como essas necessidades se revelam no caso concreto".

Entretanto, o acesso à Justiça não pode ser estudado apenas nos limites do acesso aos órgãos judiciais já existentes. Conforme Kazuo Watanabe ${ }^{13}$ : "Não se trata apenas de possibilitar o acesso à Justiça enquanto instituição estatal, e sim de viabilizar o acesso à ordem jurídica justa". Para ele, cabe ao Poder Judiciário não somente organizar os serviços que são prestados por meio de processos judiciais, como também aqueles que socorram os cidadãos de maneira mais abrangente, como a obtenção de documentos essenciais para o exercício da cidadania, e até mesmo de simples palavras de orientação jurídica.

\footnotetext{
11 THEODORO JÚNIOR, Humberto. Curso de direito processual Civil. 59 ed, atual. e ampl. Rio de Janeiro: Forense, 2018, p. 73.

12 MARINONI, Luiz Guilherme; MITIDIERO, Daniel; SARLET, Ingo Wolfgang Curso de direito constitucional. 6. ed. São Paulo: Saraiva, 2017, p. 228.

13 WATANABE, Kazuo. Acesso à Justiça e Sociedade Moderna. In: DINAMARCO, Cândido Rangel; GRINOVER, Ada Pellegrini; WATANABE, Kazuo (Coord.). Participação e Processo. RT, p. 128-135, 1988. p. 128.
} 
Revista Eletrônica de Direito Processual - REDP.

Rio de Janeiro. Ano 13. Volume 20. Número 1. Janeiro a Abril de 2019

Periódico Quadrimestral da Pós-Graduação Stricto Sensu em Direito Processual da UERJ

Patrono: José Carlos Barbosa Moreira (in mem.). ISSN 1982-7636. pp. 82-107

www.redp.uerj.br

Na concepção de Kazuo Watanabe ${ }^{14}$ são dados elementares do direito de acesso à justiça:

1) o direito à informação e perfeito conhecimento do direito substancial e à organização de pesquisa permanente a cargo de especialistas e orientada à aferição constante da adequação entre a ordem jurídica e a realidade sócio-econômica do País; 2) direito de acesso à Justiça adequadamente organizada e formada por juízes inseridos na realidade social e comprometidos com o objetivo de realização da ordem jurídica justa; 3) direito à preordenação dos instrumentos processuais capazes de promover a efetiva tutela de direitos: 4) direito à remoção de todos os obstáculos que se anteponham ao acesso efetivo à justiça com tais características.

A promoção da justiça se insere também na dimensão da assessoria jurídica popular ou privada e da consultoria jurídica. Isto porque na assessoria jurídica há uma capacitação dos espaços públicos ou privados com a finalidade de prevenir controvérsias, uma vez que há um aconselhamento contínuo às partes visando esclarecer o Direito. Já na consultoria jurídica a parte interessada procura junto aos operadores do direito um aconselhamento em face de um problema.

Essas duas dimensões extrapolam o processo judicial, dando margem a uma dimensão extrajudicial e em caráter preventivo ao litígio, posicionando o cidadão frente aos seus direitos fundamentais.

Portanto, acesso à justiça é acesso à ordem jurídica justa, ou seja, obtenção de justiça substancial, conforme apontado na Resolução nº 125/2010 do CNJ. Essa definição abarca uma série de possibilidades de realização da justiça, tanto pela autotutela (nos limites em que é permitida), como por força da autocomposição (quando as partes resolvem o conflito consensualmente), ou pela imposição da decisão por um terceiro (heterocomposição), caso tenha sido eleito pelas partes (árbitro) ou escolhido pelo Estado (magistrado). Dessa forma, deve-se olhar a ordem jurídica pela perspectiva dos destinatários das normas jurídicas, que é o povo.

\footnotetext{
${ }^{14}$ Ibid, p. 135.
} 
Revista Eletrônica de Direito Processual - REDP.

Rio de Janeiro. Ano 13. Volume 20. Número 1. Janeiro a Abril de 2019

Periódico Quadrimestral da Pós-Graduação Stricto Sensu em Direito Processual da UERJ

Patrono: José Carlos Barbosa Moreira (in mem.). ISSN 1982-7636. pp. 82-107

www.redp.uerj.br

Corroborando essa perspectiva, o Código de Processo Civil concebe a Justiça Civil dispondo não apenas de um único meio para resolução do conflito ou apenas da forma tradicional heterocompositiva, em que um terceiro resolve a ameaça ou crise de colaboração na realização do direito material entre as partes, mas de acordo com Marinoni, Mitidiero e Sarlet ${ }^{15}$ : “[...] nosso Código adota um sistema de "Justiça Multiportas”, que viabiliza diferentes técnicas para solução de conflitos - com especial ênfase na conciliação e mediação".

Dessa maneira, o acesso à justiça, como um direito fundamental, sobrepõe a dimensão do ajuizamento de ações perante o Poder Judiciário. É necessário um olhar mais profundo na busca pela real consecução da Justiça, que poderá ser realizada por meio da mediação, espécie de autocomposição, em que as próprias partes interessadas, resolvem por si mesmas, a ameaça ou crise de colaboração na realização do direito material.

\section{A MEDIAÇÃo FAMILIAR E SUAS DIMENSÕES PRÉ-PROCESSUAL E PROCESSUAL}

A tutela jurisdicional não constitui o único meio de eliminação dos conflitos. $\mathrm{Na}$ verdade, a jurisdição é a ultima ratio na tentativa de pacificação social. Os procedimentos não jurisdicionais de solução dos conflitos, como a conciliação e a mediação, são denominados de meios alternativos de pacificação social (ou equivalentes jurisdicionais). Atualmente tem-se adotado a expressão Resolução "Adequada” de Disputas para se referir aos métodos capazes de solucionar conflitos.

A mediação pode ser definida, de acordo com Fernanda Tartuce ${ }^{16}$, como um "mecanismo de abordagem consensual de controvérsias em que uma pessoa isenta e capacitada atua tecnicamente com vistas a facilitar a comunicação entre os envolvidos". A decisão caberá às partes, jamais ao mediador.

A mediação assemelha-se à conciliação, uma vez que ambas visam à autocomposição. Entretanto, são diferentes, isto porque, na conciliação, o conciliador tem

15 MARINONI, Luiz Guilherme; MITIDIERO, Daniel; SARLET, Ingo Wolfgang Curso de direito constitucional. 6. ed. São Paulo: Saraiva, 2017, p. 174.

16 TARTUCE, Fernanda. Mediação no Novo CPC: questionamentos reflexivos. Novas Tendências do Processo Civil: estudos sobre o projeto do novo Código de Processo Civil. Org.: CAMARGO, Luiz Henrique Volpe; FREIRE, Alexandre; JÚNIOR, Fredie Didier; MEDINA, José Miguel Garcia; DANTAS, Bruno; NUNES, Dierle; Miranda de Oliveira. 2013, p. 749. 
Revista Eletrônica de Direito Processual - REDP.

Rio de Janeiro. Ano 13. Volume 20. Número 1. Janeiro a Abril de 2019

Periódico Quadrimestral da Pós-Graduação Stricto Sensu em Direito Processual da UERJ

Patrono: José Carlos Barbosa Moreira (in mem.). ISSN 1982-7636. pp. 82-107

www.redp.uerj.br

participação mais ativa no processo de negociação, podendo, inclusive, sugerir soluções para o litígio, sendo indicada esta técnica para os casos em que não há vínculo anterior entre os envolvidos. Ademais, a conciliação é um processo consensual breve, envolvendo contextos conflituosos menos complexos, no qual as partes ou os interessados são auxiliados por um terceiro, neutro à disputa, a chegar a uma solução ou acordo. Já na mediação, o mediador é um facilitador do diálogo entre eles, auxiliando-os a compreender as questões e os interesses em conflito, de modo que eles possam identificar por si mesmos, soluções consensuais que gerem benefícios mútuos.

A Resolução no 125/2010, do Conselho Nacional de Justiça, instituiu, no Brasil, uma política pública de tratamento adequado dos conflitos jurídicos, com claro estímulo à solução por autocomposição. Seguindo esta orientação, o Poder Legislativo editou várias leis, inclusive o Código de Processo Civil, que expressa, em seu art. $3^{\circ}$, $\S 3^{\circ}$, que a mediação e outros métodos de solução consensual de conflitos deverão ser estimulados por juízes, defensores públicos, membros do Ministério Público, advogados, inclusive no curso do processo judicial.

Ademais, o CPC apresenta uma Seção inteira, dos arts. 165 a 175, sob o título: "Dos conciliadores e mediadores judiciais", e no art. 334, disciplina a Audiência de Conciliação ou de Mediação. Por fim, a Lei de Mediação brasileira, Lei n ${ }^{\circ}$ 13.140/2015 ${ }^{17}$ considera tal meio como a atividade técnica exercida por um terceiro imparcial que auxilia e estimula as partes a identificar ou desenvolver soluções consensuais para a controvérsia.

É fato que o presente estudo se delimita às mediações que ocorrem nos conflitos de família, destacando-se tal método por facilitar o diálogo entre as pessoas para que possam efetivar novas formas de relacionamento, buscando, dessa forma, a continuidade dos vínculos familiares.

Existem duas dimensões da mediação: a pré-processual e a processual. A primeira ocorre antes mesmo da propositura da ação, nos Centros Judiciários de Solução de Conflitos (CEJUSC), em que o interessado comparece neste órgão ou remete pretensão via e-mail com os dados essenciais. O funcionário colherá o pedido, sem reduzi-lo a termo, emitindo no ato, carta convite à parte contrária informando os documentos necessários, a

17 BRASIL. Lei $n^{\circ}$ 13.140/2015. Dispõe sobre a mediação entre particulares como meio de solução de controvérsias e sobre a autocomposição de conflitos no âmbito da administração pública; altera a Lei no 9.469, de 10 de julho de 1997, e o Decreto no 70.235, de 6 de março de 1972; e revoga o § 2o do art. 6음a Lei no 9.469, de 10 de julho de 1997. Diário Oficial da União, Brasília, 29 de jun. 2015. 
Revista Eletrônica de Direito Processual - REDP.

Rio de Janeiro. Ano 13. Volume 20. Número 1. Janeiro a Abril de 2019

Periódico Quadrimestral da Pós-Graduação Stricto Sensu em Direito Processual da UERJ

Patrono: José Carlos Barbosa Moreira (in mem.). ISSN 1982-7636. pp. 82-107

www.redp.uerj.br

data, hora e local da sessão de mediação, sendo recomendável sua realização no prazo de 30 (trinta) dias. É fato que, de acordo com Marco Aurélio Gastaldi Buzzi ${ }^{18}$ : “[...] o convite poderá ser feito por qualquer meio idôneo de comunicação, podendo até mesmo ser entregue pelo solicitante, se ainda houver algum diálogo com a parte contrária [...]”.

A sessão de mediação será realizada e, concluída e obtido o acordo, será esse homologado por sentença do Juiz Coordenador do CEJUSC, após a manifestação do representante do Ministério Público, se for o caso, com registro em livro próprio, mas sem distribuição. O termo do acordo poderá ser arquivado em meio digital e os documentos restituídos aos interessados.

Posteriormente, se o acordo obtido for descumprido, o interessado munido do respectivo termo de acordo poderá ajuizar ação de execução de título judicial, segundo as regras de competência, sendo que apenas nesse momento haverá distribuição.

O tempo necessário para a realização da sessão pode variar de caso para caso, sendo recomendável que sejam agendadas com intervalo de 30 (trinta) a 40 (quarenta) minutos, permitindo-se a designação de sessão em continuação, com intervalo de tempo maior, desde que realizada pelo mesmo conciliador ou mediador e dentro do prazo de 30 (trinta) dias.

Além disso, as sessões de mediação poderão ser redesignadas quando as partes solicitarem ou quando alguma das partes não comparece devidamente munida com os documentos necessários para a realização da sessão, ou ainda, quando o Juiz ou Promotor solicitarem.

A mediação processual é efetivada no curso de uma demanda já instaurada, sendo conduzida por mediadores judiciais (previamente cadastrados e habilitados segundo as regras do respectivo Tribunal) designados pelo juiz da causa.

A mediação nas ações de família é um ato obrigatório. De acordo com o art. 695 do CPC, recebida a petição inicial, o juiz ordenará a citação do réu para comparecer à audiência de mediação e conciliação. Importante destacar que as partes não são obrigadas a negociar, mas apenas a comparecer à primeira reunião, na qual se oportuniza às mesmas a opção da negociação assistida.

${ }^{18}$ BUZZI, Marco Aurélio Gastaldi. et al. Guia de Conciliação e Mediação Judicial: orientação para instalação de CEJUSC. Brasília/DF: Conselho Nacional de Justiça, 2015, p. 21. 
Revista Eletrônica de Direito Processual - REDP.

Rio de Janeiro. Ano 13. Volume 20. Número 1. Janeiro a Abril de 2019

Periódico Quadrimestral da Pós-Graduação Stricto Sensu em Direito Processual da UERJ

Patrono: José Carlos Barbosa Moreira (in mem.). ISSN 1982-7636. pp. 82-107

www.redp.uerj.br

O mandado de citação conterá apenas os dados necessários à audiência e deverá estar desacompanhado de cópia da petição inicial, assegurado ao réu o direito de examinar seu conteúdo a qualquer tempo. É fato que a citação ocorrerá com antecedência mínima de quinze dias da data designada para a audiência.

$\mathrm{Na}$ audiência, as partes deverão estar acompanhadas de seus advogados ou de defensores públicos.

A sessão de mediação não segue os moldes de uma "audiência judicial" fundamentada na adversariedade e na argumentação direcionada ao convencimento do magistrado, uma vez que sua característica é a consensualidade.

A possibilidade de ocorrência de várias sessões ou reuniões de mediação é bastante positiva, uma vez que é difícil o êxito com apenas uma sessão de mediação familiar. Ressalta-se que o procedimento de mediação processual deverá ser concluído em até sessenta dias, contados da primeira sessão, salvo quando as partes, de comum acordo, requererem sua prorrogação. Além disso, os mediandos podem requerer a suspensão do processo por prazo suficiente, para a solução consensual do litígio.

Os acordos da fase processual serão homologados pelo Juiz do Cartório competente, que determinará o arquivamento do processo. Por outro lado, não sendo realizado o acordo incide-se as normas do procedimento comum, observado o art. 335 do Código de Processo Civil.

Portanto, as mediações processuais ocorrem quando já existe um processo tramitando na Justiça. Já as mediações pré-processuais ocorrem antes que um processo seja distribuído, são mais informais e rápidas e podem funcionar evitando que uma demanda necessite ser resolvida na justiça.

\section{CEJUSC: DIRETRIZES E ORGANIZAÇÃO}

O Conselho Nacional de Justiça aprovou, em 29 de novembro de 2010, a Resolução $\mathrm{n}^{\mathrm{o}} 125$, dispondo sobre a Política Judiciária Nacional de tratamento adequado dos conflitos de interesses. Trata-se de política pública cuja efetivação é de incumbência de uma rede constituída por todos os órgãos do Poder Judiciário e por entidades públicas e privadas parceiras, inclusive universidades e instituições de ensino, para que seja assegurado o 
Revista Eletrônica de Direito Processual - REDP.

Rio de Janeiro. Ano 13. Volume 20. Número 1. Janeiro a Abril de 2019

Periódico Quadrimestral da Pós-Graduação Stricto Sensu em Direito Processual da UERJ

Patrono: José Carlos Barbosa Moreira (in mem.). ISSN 1982-7636. pp. 82-107

www.redp.uerj.br

acesso à ordem jurídica justa, mediante o tratamento adequado dos problemas jurídicos e conflitos de interesses.

Para viabilizar esta política pública, estabeleceu-se uma estrutura organizacional chefiada pelo Conselho Nacional de Justiça, cuja incumbência, nos termos do art. $4^{\circ}$ da Resolução no 125 de 2010, é formular o programa com o objetivo de promover ações de incentivo à autocomposição de litígios e à pacificação social.

Dessa forma, no âmbito regional, cabe aos Tribunais criarem Núcleos Permanentes de Métodos Consensuais de Solução de Conflitos (NUPEMECs), nos termos do art. $7^{\circ}$ da Resolução 125 de 2010, os quais serão coordenados por magistrados e compostos por magistrados da ativa ou aposentados e servidores, preferencialmente atuantes na área. De acordo com Marco Aurélio Gastaldi Buzzi ${ }^{19}$, esses núcleos também são denominados de cérebro autocompositivo do tribunal. Isto porque possui competência de instalar os Centros Judiciários de Solução de Conflitos e planejar de forma centralizada essa política pública no respectivo Tribunal.

Ademais, nos termos do art. 7º, VII e VIII, da Resolução no 125 de 2010, cabe ao NUPEMEC criar e manter cadastro de mediadores e conciliadores, regulando o processo de inscrição e de desligamento, como também regulamentar, se for o caso, a remuneração de conciliadores e mediadores. É fato que o NUPEMEC foi incluído como órgão do TJMG, por intermédio da edição da Emenda Regimental n ${ }^{\circ} 11$, em 29 de maio de $2017^{20}$.

Além disso, dentro dessa estrutura organizacional, encontram-se os Centros Judiciários de Solução de Conflitos (CEJUSCs), criados pelos Tribunais e com o objetivo primordial de realizar as sessões de conciliação e mediação do tribunal. Serão instalados CEJUSCs em todas as Comarcas com mais de uma Vara. Na região onde já exista um Centro instalado, dependendo da demanda, poderão ser criados postos desse CEJUSC Central.

O CEJUSC deve necessariamente abranger setor de solução de conflitos préprocessual, processual e de cidadania, conforme art. 10 da Resolução 125 de 2010. O setor pré-processual deverá, obrigatoriamente, receber causas cíveis e de família e será

\footnotetext{
19 BUZZI, Marco Aurélio Gastaldi. et al. Guia de Conciliação e Mediação Judicial: orientação para instalação de CEJUSC. Brasília/DF: Conselho Nacional de Justiça, 2015.

${ }^{20}$ MINAS GERAIS. Tribunal de Justiça. Emenda Regimental no 11, de 29 de maio de 2017. Altera a redação do inciso XIV do art. $9^{\circ}$ e acrescenta o inciso VII ao art. 31, todos do Regimento Interno do Tribunal de Justiça do Estado de Minas Gerais. Diário da Justiça Eletrônico, Belo Horizonte, 30 mai. 2017.
} 
Revista Eletrônica de Direito Processual - REDP.

Rio de Janeiro. Ano 13. Volume 20. Número 1. Janeiro a Abril de 2019

Periódico Quadrimestral da Pós-Graduação Stricto Sensu em Direito Processual da UERJ

Patrono: José Carlos Barbosa Moreira (in mem.). ISSN 1982-7636. pp. 82-107

www.redp.uerj.br

encarregado das mediações e conciliações pré-processuais, que ocorrem antes que um processo seja distribuído, sendo um meio mais informal e rápido evitando que uma demanda necessite ser resolvida na justiça. O setor processual é encarregado das mediações e conciliações processuais que ocorrem quando já existe um processo tramitando na justiça e podem ser solicitadas a qualquer momento, pelo juiz, pelos advogados ou pelas partes. No setor de cidadania poderão ser disponibilizados serviços de orientação e encaminhamento ao cidadão, para que este obtenha documentos.

De acordo com Marco Aurélio Gastaldi Buzzi, 21 “O CEJUSC deverá funcionar de segunda a sexta-feira, durante 8 (oito) horas diárias, sem fechar na hora do almoço, dentro de algum dos seguintes períodos: das $9 \mathrm{~h}$ às $17 \mathrm{~h}$, das $10 \mathrm{~h}$ às $18 \mathrm{~h}$, ou das $11 \mathrm{~h}$ às $19 \mathrm{~h}$ ”.

Os Centros contarão com um Juiz Coordenador e se necessário, com um adjunto, devidamente capacitados, aos quais caberão a sua administração e a homologação de acordos, a supervisão do serviço de conciliadores e mediadores, o acompanhamento da capacitação e da atuação de conciliadores e mediadores e sua seleção, com a inclusão e a exclusão do cadastro do respectivo tribunal, sendo necessário que estes conheçam não só o funcionamento dos CEJUSCs com seus procedimentos, mas também a conciliação e a mediação, com certa propriedade.

Conforme Marco Aurélio Gastaldi Buzzi, ${ }^{22}$ "O CEJUSC terá um servidor (escrevente técnico judiciário), com cargo em comissão de Chefe de Seção Judiciário, que poderá ser indicado, desde logo, pelo Juiz Coordenador do Centro”. Este servidor, antes de assumir o cargo, deverá fazer o curso de capacitação Módulo Servidor, cujo acesso online será solicitado pelo Juiz Coordenador do Centro ao Diretor da Escola da Magistratura ou para entidades habilitadas pelo Núcleo.

O CEJUSC será composto também por servidores com dedicação exclusiva, todos capacitados em métodos consensuais de solução de conflitos e pelo menos um deles capacitado para a triagem e encaminhamento adequado de casos. Estes servidores do Judiciário serão cedidos pelas Varas da Comarca. Por meio de termo de convênio específico para este fim poderá o CEJUSC ter funcionários e estagiários da Prefeitura, de instituições de ensino e de outras entidades parceiras.

${ }^{21}$ BUZZI, Marco Aurélio Gastaldi. et al. Guia de Conciliação e Mediação Judicial: orientação para instalação de CEJUSC. Brasília/DF: Conselho Nacional de Justiça, 2015, p. 27.

${ }^{22}$ Ibid., p. 28. 
Revista Eletrônica de Direito Processual - REDP.

Rio de Janeiro. Ano 13. Volume 20. Número 1. Janeiro a Abril de 2019

Periódico Quadrimestral da Pós-Graduação Stricto Sensu em Direito Processual da UERJ

Patrono: José Carlos Barbosa Moreira (in mem.). ISSN 1982-7636. pp. 82-107

www.redp.uerj.br

Ademais, todos os conciliadores e mediadores que atuam no Centro devem ser capacitados e cadastrados perante o NUPEMEC, cabendo ao Juiz Coordenador selecionálos, exigindo certificado de conclusão de curso de capacitação, uma vez que a atuação sem capacitação e cadastro no NUPEMEC configura ato irregular.

\section{CEJUSC EM UBERLÂNDIA: ESTRUTURA E FUNCIONAMENTO}

Antes de compreender o CEJUSC em Uberlândia ${ }^{23}$ é essencial enfatizar que, no Estado de Minas Gerais, a instalação e o funcionamento dos Centros Judiciários de Solução de Conflitos ocorreram por meio da Resolução nº 682 de 24 de novembro de $2011^{24}$, instituindo, em seu art. $1^{\circ}$, que os CEJUSCs serão instalados nas comarcas do Estado de Minas Gerais, mediante Portaria-Conjunta do Presidente, do Terceiro VicePresidente do Tribunal de Justiça e do Corregedor-Geral de Justiça.

Seguindo essa diretiva, a instalação do Centro Judiciário de Solução de Conflitos e Cidadania (CEJUSC) na comarca de Uberlândia foi realizada no dia 18 de maio de 2016, por meio da Portaria $n^{\circ} 500^{25}$ expedida pelo Presidente, $3^{\circ}$ Vice-Presidente do Tribunal de Justiça e pelo Corregedor-Geral de Justiça do Estado de Minas Gerais.

E, por meio da Portaria $\mathrm{n}^{\mathrm{o}} 3335^{26}$, em 16 de maio de 2016, o presidente do Tribunal de Justiça do Estado de Minas Gerais, à época, o Desembargador Pedro Carlos Bitencourt Marcondes, nos termos do art. $9^{\circ}$ da Resolução n ${ }^{\circ} 125$ do Conselho Nacional da Justiça, nomeou como Juiz Coordenador do Centro Judiciário de Solução de Conflitos de Uberlândia, o Juiz de Direito, Dr. Carlos José Cordeiro e na função de Coordenador Adjunto, o Juiz de Direito Dr. Walner Barbosa Milward de Azevedo.

\footnotetext{
${ }^{23}$ O CEJUSC de Uberlândia está localizado no Palácio da Justiça Rondon Pacheco, na Sala 602. O local tem acesso ao ponto de ônibus, em frente ao fórum facilitando o acesso dos interessados ao local.

${ }^{24}$ MINAS GERAIS. Tribunal de Justiça. Resolução no 682 de 24 de novembro de 2011. Dispõe sobre a instalação e o funcionamento dos Centros Judiciários de Solução de Conflitos e Cidadania nas comarcas do Estado de Minas Gerais. Diário da Justiça Eletrônico, Belo Horizonte, 25 nov. 2011.

${ }^{25}$ MINAS GERAIS. Tribunal de Justiça. Portaria Conjunta no 500/PR/2016. Instala o Centro Judiciário de Solução de Conflitos e Cidadania da Comarca de Uberlândia. Diário da Justiça Eletrônico, Belo Horizonte, 16 mai. 2016.

${ }^{26}$ MINAS GERAIS. Tribunal de Justiça. Portaria no 3335/PR/2016. Designa Juiz Coordenador e Juiz Coordenador Adjunto do Centro Judiciário de Solução de Conflitos e Cidadania da Comarca de Uberlândia. Diário da Justiça Eletrônico, Belo Horizonte, 16 mai. 2016.
} 
Revista Eletrônica de Direito Processual - REDP.

Rio de Janeiro. Ano 13. Volume 20. Número 1. Janeiro a Abril de 2019

Periódico Quadrimestral da Pós-Graduação Stricto Sensu em Direito Processual da UERJ

Patrono: José Carlos Barbosa Moreira (in mem.). ISSN 1982-7636. pp. 82-107

www.redp.uerj.br

Em entrevista com a servidora Cláudia Maria Lukschal Amaral Resende ${ }^{27}$, o corpo

fixo do CEJUSC é formado pela mesma, por Daniela Landin Negreiros ${ }^{28}$ e Isabela Moreira

Gonçalves $^{29}$. Ademais existem servidores do Tribunal de Justiça de Minas Gerais, nove estagiários remunerados pelo TJMG e os mediadores, que no total de dez, são voluntários. Todos eles devidamente capacitados com o curso teórico de capacitação em conciliação e mediação.

Os mediadores também são habilitados enquanto mediadores, tanto pelo TJMG quanto pelo CNJ. O curso teórico que devem fazer é o Curso em Capitação em Conciliação ou Mediação, composto por 40 (quarenta) horas. A Escola Judicial Desembargador Edésio Fernandes promove os cursos de conciliação à distância e de mediação presenciais. Após a conclusão da parte teórica há a realização do estágio supervisionado, composto por $60 \mathrm{~h}$ (sessenta horas).

Para aqueles que querem se habilitar como conciliador, são 60 (sessenta) horas. Os conciliadores devem atender apenas casos de conciliação e emitir relatórios das sessões de conciliação. Já para os interessados em se tornarem mediadores, dos 10 (dez) casos que precisam atender, 7 (sete) são de conciliação e 3 (três) de mediação.

Ademais, para ser mediador, o indivíduo deve ser formado há 2 (dois) anos em qualquer curso de graduação. E para ser conciliador não é essencial ser formado em curso superior. Ambos começam observando as sessões para depois desempenharem o papel de conciliadores e mediadores.

É fato que as sessões de mediação são formadas por 3 (três) pessoas: o mediador, comediador e observador. E procura-se nelas que os dois primeiros, sendo de formações acadêmicas distintas atuem conjuntamente para que ocorra a multidisciplinaridade e um melhor resultado nas mediações, uma vez que as diferentes áreas do conhecimento se completam e interpenetram. Por exemplo, a psicologia completa o direito, com as suas regulamentações.

O CEJUSC Uberlândia tem três setores: pré-processual, processual e cidadania.

\footnotetext{
${ }^{27}$ Entrevista realizada em 04 de julho de 2018 com a Sra. Cláudia Maria Lukschal Amaral Resende, que é psicóloga judicial e supervisora do CEJUSC Uberlândia, concursada pelo Tribunal de Justiça de Minas Gerais.

${ }^{28}$ Daniela Landin Negreiros é formada em Direito, oficial de Apoio Judicial, concursada pelo Tribunal de Justiça de Minas Gerais.

${ }^{29}$ Isabela Moreira Gonçalves é assistente administrativa do Tribunal de Justiça de Minas Gerais.
} 
Revista Eletrônica de Direito Processual - REDP.

Rio de Janeiro. Ano 13. Volume 20. Número 1. Janeiro a Abril de 2019

Periódico Quadrimestral da Pós-Graduação Stricto Sensu em Direito Processual da UERJ

Patrono: José Carlos Barbosa Moreira (in mem.). ISSN 1982-7636. pp. 82-107

www.redp.uerj.br

Atende-se no setor processual as dez varas cíveis e as cinco varas de família da Comarca, as quais encaminham ao CEJUSC os processos, e o juiz coordenador pode homologar os acordos. Como o objeto do trabalho são as mediações familiares, é fato que 90\% (noventa por cento) das causas de família encaminhadas são de divórcio, dissolução de união estável com guarda e alimentos.

Ocorrem as Audiências de Mediação no início do processo e nestas, os mediadores e estagiários, convidam as partes à mediação. Se as partes concordam, o processo é suspenso por 60 (sessenta) dias. Neste período são realizadas as sessões de mediação. A Resolução $n^{\circ} 125$ de 2010 expõe sobre duas a cinco sessões, uma vez por semana. Entretanto, existem casos que é necessário um número maior de sessões. Esse processo de sessões dura aproximadamente um mês, dependendo se for entre duas a cinco sessões. E a qualquer tempo os mediandos podem interromper e encerrarem a mediação.

Nota-se que os advogados têm auxiliado os mediadores. Existem processos complicados, que tramitavam por mais de dez anos em que as partes foram dialogando e com o auxílio dos advogados ocorreu a solução do conflito.

No setor pré-processual o indivíduo não precisa vir acompanhado de advogado e defensor público. Aquele chega no CEJUSC, expõe sua demanda, os funcionários orientam e questionam se é do interesse da pessoa resolver o conflito e faz-se uma atermação informal. Estabelece-se uma data para a sessão de mediação pré-processual e a pessoa, na posse do endereço da outra, leva a carta para que esta compareça no CEJUSC. A pessoa entrega a carta. É convite, não é citação e intimação. Se a pessoa não informar o endereço da outra pessoa envolvida não há possibilidade de realização da sessão. Pode-se optar por enviar a carta por correio, o que na prática é raro. Existem situações que o conflito está grande e o outro indivíduo não comparece no CEJUSC. Entretanto, observa-se que a grande maioria comparece. Há um diálogo na sessão. E todo o pré-processo é encaminhado para o Juiz Coordenador, Dr. Carlos José Cordeiro, para que homologue o acordo. Este se torna título executivo judicial, cujo descumprimento pode gerar uma execução.

O que se objetiva na fase pré-processual é atender aos indivíduos carentes e evitar a judicialização do conflito.

Existem casos que envolvem menores e é imprescindível a presença do Ministério Público. 
Revista Eletrônica de Direito Processual - REDP.

Rio de Janeiro. Ano 13. Volume 20. Número 1. Janeiro a Abril de 2019

Periódico Quadrimestral da Pós-Graduação Stricto Sensu em Direito Processual da UERJ

Patrono: José Carlos Barbosa Moreira (in mem.). ISSN 1982-7636. pp. 82-107

www.redp.uerj.br

No setor de Cidadania, realiza-se a orientação e o encaminhamento dos jurisdicionados. Em algumas comarcas tem ação global em que se realiza, por exemplo, corte de cabelo e emissão de carteira de identidade.

O CEJUSC Uberlândia tem se descentralizado, com a presença dos Postos de Atendimento Pré-Processual (PAPREs). Os PAPREs são unidades voltadas para a conciliação de demandas que ainda não se tornaram judiciais e estão sendo criados a partir de convênio com o Tribunal de Justiça de Minas Gerais (TJMG) e diversas Universidades, como a Universidade Federal de Uberlândia, Centro Universitário do Triângulo, Faculdade Pitágoras, Pontifícia Universidade Católica de Minas Gerais e Faculdade UNA. Nestes locais se realizam acordos, que são encaminhados para o CEJUSC e o Juiz Coordenador Dr. Carlos José Cordeiro, no nível pré-processual pode homologar os acordos.

\section{A EFETIVIDADE DA MEDIAÇÃO FAMILIAR NO CEJUSC EM UBERLÂNDIA}

O princípio da efetividade ou da máxima coincidência possível não é previsto expressamente no texto constitucional e no Código de Processo Civil, mas decorre do devido processo legal. O processo efetivo é um dos três pilares que sustentam a nova dimensão do processo justo: a tutela efetiva, célere e adequada. A noção de processo justo está intimamente ligada à efetividade da prestação jurisdicional, de modo a garantir a todos o acesso à justiça, em tempo que não extrapole os limites do razoável. Dessa forma, é essencial a justiça efetiva aparelhar-se para propiciar ao titular do direito um provimento que seja contemporâneo à lesão ou à sua ameaça, consistindo em solução justa para o litígio. O processo justo e efetivo, portanto, deve viabilizar uma solução rápida para a disputa apresentada ao juiz, mas sem deixar de observar e respeitar os direitos e as garantias fundamentais das partes.

Elpídio Donizeti ${ }^{30}$ afirma que, "De acordo com o princípio da efetividade, àquele que tem razão, o processo deve garantir e conferir, na medida do possível, justamente o bem da vida a que ele teria direito se não precisasse se valer do processo".

Assim, o processo efetivo não se limita ao provimento formal: a efetividade abrange também os meios executivos capazes de concretizar o direito material.

\footnotetext{
${ }^{30}$ DONIZETTI, Elpídio. Curso didático de direito processual civil. 21 ed. rev. atual. e ampl. São Paulo: Atlas, 2018, p. 58.
} 
Revista Eletrônica de Direito Processual - REDP.

Rio de Janeiro. Ano 13. Volume 20. Número 1. Janeiro a Abril de 2019

Periódico Quadrimestral da Pós-Graduação Stricto Sensu em Direito Processual da UERJ

Patrono: José Carlos Barbosa Moreira (in mem.). ISSN 1982-7636. pp. 82-107

www.redp.uerj.br

Ademais, processo efetivo não é sinônimo de processo célere, uma vez que o primeiro perdurará pelo prazo compatível com a complexidade do direito discutido. Será célere sempre quando possível.

Desde a instalação do CEJUSC em Uberlândia, em 18 de maio de 2016, até o presente momento, observa-se a efetividade da mediação, como também número considerável de acordos nas mediações familiares pré-processuais e processuais, como demonstrado nos gráficos, situados abaixo.

Em relação aos dados fornecidos pela Supervisora do CEJUSC Uberlândia, Cláudia Maria Lukschal Amaral Resende e dispostos no site do Tribunal de Justiça de Minas Gerais, nos casos pré-processuais atermados ocorridos em 2016 (julho a dezembro), 100\% (cem por cento) obtiveram acordo por meio da mediação; o número de acordos ocorridos em sessões de mediação em 2017 foi 50\% (cinquenta por cento) e em 2018 (fevereiro a junho), dos 58 casos atermados, 9\% (nove por cento) obtiveram acordo por meio da mediação pré-processual, $5 \%$ (cinco por cento) não resultaram em acordo e $25 \%$ (vinte e cinco por cento) decorreram de não adesão, ou seja, as duas ou uma das partes não compareceram à sessão de mediação. Portanto em 2016, 100\% (cem por cento) dos conflitos foram solucionados; em 2017 esse percentual passa a 50\% (cinquenta por cento), e em 2018 nota-se que, pelo fato de 60\% (sessenta por cento) dos pré-processos ainda estarem em andamento, o número de acordos foi no total de $9 \%$ (nove por cento).

Em relação aos dados fornecidos pela Oficial de Apoio Judicial, Daniela Landin Negreiros e dispostos no site do Tribunal de Justiça de Minas Gerais, observou-se que no processo recebido pelo CEJUSC, de Uberlândia, em 2016 (julho a dezembro) ocorreu acordo, por meio da mediação processual. Em 2017, dos processos recebidos, 27,27\% (vinte e sete vírgula vinte e sete por cento) obtiveram acordo por meio da mediação processual, 63,63\% (sessenta e três vírgula sessenta e três por cento) estão em andamento e 9,09\% (nove vírgula zero nove por cento) não resultaram em acordo. Em 2018 (fevereiro a maio), o percentual de acordo nos processos foi de 18,18\% (dezoito vírgula dezoito por cento), $72,72 \%$ (setenta e dois vírgula setenta e dois por cento) dos processos estão em andamento e 9,09\% (nove vírgula zero nove por cento) não resultaram em acordo.

O que se nota é que em 2016, 100\% (cem por cento) dos conflitos foram solucionados. Por outro lado, nos anos de 2017 e 2018, há uma quantidade expressiva de processos em andamento, 63,63\% (sessenta e três vírgula sessenta e três por cento) e 
Revista Eletrônica de Direito Processual - REDP.

Rio de Janeiro. Ano 13. Volume 20. Número 1. Janeiro a Abril de 2019

Periódico Quadrimestral da Pós-Graduação Stricto Sensu em Direito Processual da UERJ

Patrono: José Carlos Barbosa Moreira (in mem.). ISSN 1982-7636. pp. 82-107

www.redp.uerj.br

$72,72 \%$ (setenta e dois vírgula setenta e dois por cento) respectivamente. E, em virtude disso, não foi possível obter um número total de acordos. Mas o que se observa é que em 2017 , dos processos solucionados, $75 \%$ (setenta e cinco por cento) obtiveram acordo e em 2018 foi um percentual de 66,66\% (sessenta e seis vírgula sessenta e seis por cento).

Somado a isto, conforme exposto abaixo no gráfico extraído do Relatório de Atividades 2016/2018 do Tribunal de Justiça de Minas Gerais, da $3^{\text {a }}$ Vice-Presidência, relatório que não foi publicado, verifica-se um aumento do número de acordos obtidos em conciliações e em mediações nos Centros Judiciários de Solução de Conflitos, nos anos de 2016 e 2017, estando Uberlândia na terceira posição em relação a Uberaba e Juiz de Fora.

De todo o exposto, verifica-se a efetividade da mediação pré-processual e processual, em virtude do fato de que o processo deve garantir e conferir, na medida do possível, o bem da vida que a parte teria direito se não precisasse se valer do mesmo. Notase que, com a obtenção do acordo e possível homologação está se conferindo o bem da vida que os jurisdicionados pleitearam. E, além disso, mesmo que não haja acordo, a mediação pré-processual e processual é efetiva, uma vez que "O objetivo primordial da mediação é facilitar o diálogo entre as partes e a compreensão dos seus interesses mesmo que, a despeito disso, não se realize acordo [...]"31. Ou seja, na mediação é possível trabalhar o conflito, possibilitando que os indivíduos em conflito construam suas relações, sendo o acordo uma mera consequência.

Ademais, uma nova realidade está se formando intimamente ligada ao movimento de acesso à justiça, iniciado na década de 1970, clamando-se para que este seja melhor na perspectiva do jurisdicionado, ou seja, na solução da lide sociológica, além da mera lide processual. Ou seja, na complexidade das relações familiares, por meio da mediação, permite-se identificar o verdadeiro interesse que move a situação de discórdia, além do pedido que se faz em relação a outra parte do conflito.

Somado a isto, o modelo tradicional de jurisdição na maioria das vezes, não acarreta a pacificação social, uma vez que apresenta a conflituosidade, o que alguns autores denominam de ganha/perde ou linguagem binária. Entretanto, a tendência mundial

\footnotetext{
${ }^{31}$ CORDEIRO, Carlos José; DINIZ, Priscila Aparecida Lamana Diniz. A Mediação no Direito das Famílias e a Resolução $n^{\circ}$ 125/2010 do Conselho Nacional de Justiça: Perspectivas da Mediação enquanto política judiciária. In: CORDEIRO, Carlos José; GOMES, Josiane Araújo (Coord.). 1 v. Temas contemporâneos de direito das famílias. São Paulo: Editora Pillares, 2013. p. 483-503.
} 
Revista Eletrônica de Direito Processual - REDP.

Rio de Janeiro. Ano 13. Volume 20. Número 1. Janeiro a Abril de 2019

Periódico Quadrimestral da Pós-Graduação Stricto Sensu em Direito Processual da UERJ

Patrono: José Carlos Barbosa Moreira (in mem.). ISSN 1982-7636. pp. 82-107

www.redp.uerj.br

é a adoção de modelos consensuais no molde ganha/ganha para transformar as controvérsias.

Por isto, a mediação familiar, seja no âmbito pré ou processual é efetiva, uma vez que objetiva conduzir as partes a uma melhor continuidade na vida familiar após a ruptura da mesma.

\section{CONCLUSÃO}

A expressão acesso à Justiça determina o sistema pelo qual as pessoas podem reivindicar seus direitos e resolver seus litígios sob os auspícios do Estado e deve ser igualmente acessível a todos e produzir resultados que sejam individual e socialmente justos.

Especificamente, na terceira onda de acesso à justiça proposta por Capelletti e Garth, que centra sua atenção no conjunto geral de instituições e mecanismos, pessoas e procedimentos utilizados para processar e prevenir conflitos nas sociedades modernas, verifica-se que o Centro Judiciário de Solução de Conflitos de Uberlândia é um órgão que garante o acesso à justiça aos cidadãos, através da mediação familiar.

Somado a isto, é direito fundamental do cidadão o acesso à justiça, exposto no art. $5^{\circ}, \mathrm{XXXV}$, da Constituição Federal, garantindo que a lei não excluirá da apreciação do Poder Judiciário lesão ou ameaça a direito.

$\mathrm{O}$ acesso à Justiça, primordialmente, consiste em viabilizar o acesso à ordem jurídica justa. Assim, cabe ao Poder Judiciário não somente organizar os serviços que são prestados por meio de processos judiciais, como também aqueles que socorram os cidadãos de maneira mais abrangente. E o CEJUSC de Uberlândia faz isto de maneira eficiente com os seus três setores: pré-processual, em que se resolve questões antes que o processo seja distribuído, evitando que uma demanda necessite ser resolvida na justiça, sendo um meio mais informal e rápido; processual, em que se efetivam as mediações em processos que estão tramitando na justiça e no setor de cidadania, em que se realiza a orientação e o encaminhamento dos jurisdicionados. Nota-se, portanto, que o objetivo do artigo que é apresentar a estrutura e funcionamento do Centro Judiciário de Solução de Conflitos de Uberlândia foi cumprido. 
Revista Eletrônica de Direito Processual - REDP.

Rio de Janeiro. Ano 13. Volume 20. Número 1. Janeiro a Abril de 2019

Periódico Quadrimestral da Pós-Graduação Stricto Sensu em Direito Processual da UERJ

Patrono: José Carlos Barbosa Moreira (in mem.). ISSN 1982-7636. pp. 82-107

www.redp.uerj.br

As mediações familiares que ocorrem no CEJUSC Uberlândia, seja no âmbito pré ou processual, destacam-se por ser um método em que uma pessoa isenta e capacitada atua tecnicamente com vistas a facilitar a comunicação entre os envolvidos, possibilitando-se o diálogo entre eles para que estes possam efetivar novas formas de relacionamento e buscar a continuidade dos vínculos familiares.

E, diante dos gráficos e tabelas expostas, verifica-se um aumento do número de acordos obtidos em conciliações e em mediações nos Centros Judiciários de Solução de Conflitos, nos anos de 2016 e 2017, estando o CEJUSC Uberlândia na terceira posição em relação a outras cidades mineiras, Uberaba e Juiz de Fora.

De todo o exposto, verifica-se a efetividade da mediação pré-processual e processual, em virtude do fato de que o processo deve garantir e conferir, na medida do possível, o bem da vida a que a parte teria direito se não precisasse se valer do mesmo. Portanto, com a obtenção do acordo e sua homologação está se conferindo o bem da vida que os jurisdicionados pleitearam. Ademais, mesmo que não haja acordo, a mediação préprocessual e processual é efetiva uma vez que o objetivo primordial da mediação é facilitar o diálogo entre as partes e a compreensão dos seus interesses e a sua maior relevância encontra-se no fato de viabilizar a continuidade dos vínculos.

Portanto, no moderno Estado Democrático de Direito, o acesso à justiça não se resume ao direito de ser ouvido em juízo e de obter uma resposta qualquer do órgão jurisdicional, mas hoje se compreende o direito a uma tutela efetiva e justa para todos os interesses dos particulares agasalhados pelo ordenamento jurídico. E o que se nota é que o CEJUSC Uberlândia tem garantido aos cidadãos o direito fundamental ao acesso à justiça, com uma tutela efetiva e justa, por meio das mediações familiares.

Tabela 1 - Estatística da Mediação Familiar pré-processual em Uberlândia

\begin{tabular}{|l|l|l|l|l|l|}
\hline ANO & $\begin{array}{l}\text { CASOS } \\
\text { ATERMADOS }\end{array}$ & $\begin{array}{l}\text { NÃO } \\
\text { ADESÃO }\end{array}$ & $\begin{array}{l}\text { SEM } \\
\text { ACORDO }\end{array}$ & $\begin{array}{l}\text { EM } \\
\text { ANDAMENTO }\end{array}$ & $\begin{array}{l}\text { TOTAL } \\
\text { DE } \\
\text { ACORDO }\end{array}$ \\
\hline $\begin{array}{l}\text { (jo16 } \\
\text { julho a a } \\
\text { dezembro) }\end{array}$ & 4 & 0 & 0 & 0 & $4(100 \%)$ \\
\hline
\end{tabular}


Revista Eletrônica de Direito Processual - REDP.

Rio de Janeiro. Ano 13. Volume 20. Número 1. Janeiro a Abril de 2019

Periódico Quadrimestral da Pós-Graduação Stricto Sensu em Direito Processual da UERJ

Patrono: José Carlos Barbosa Moreira (in mem.). ISSN 1982-7636. pp. 82-107

www.redp.uerj.br

\begin{tabular}{|l|l|l|l|l|l|}
\hline \hline $\mathbf{2 0 1 7}$ & 16 & 0 & $8(50 \%)$ & 0 & $8(50 \%)$ \\
\hline $\begin{array}{l}\mathbf{2 0 1 8} \\
\text { (fevereiro } \\
\text { a junho) }\end{array}$ & 58 & $15(25 \%)$ & $3(5 \%)$ & $35(60 \%)$ & $5(9 \%)$ \\
\\
\hline
\end{tabular}

<http://www.tjmg.jus.br/portal-tjmg/acoes-e-programas/conciliacao-mediacao-ecidadania.htm\#.W0Zyh9JKiM->, acesso em 08 set. 2018.

Tabela 2 - Estatística da mediação familiar processual em Uberlândia

\begin{tabular}{|l|l|l|l|l|l|}
\hline ANO & PROCESSOS & NÃO & SEM & EM & TOTAL \\
RECEBIDOS & ADESÃO & ACORDO & ANDAMENTO & $\begin{array}{l}\text { DE } \\
\text { ACORDO }\end{array}$ \\
\hline $\begin{array}{l}\text { a16 (julho } \\
\text { dezembro) }\end{array}$ & 1 & 0 & 0 & 0 & $1(100 \%)$ \\
\hline $\begin{array}{l}\mathbf{2 0 1 7} \\
\text { (fevereiro a }\end{array}$ & 11 & 0 & $1(9,09 \%)$ & $7(63,63 \%)$ & $3(27,27 \%)$ \\
maio) & 11 & 0 & $1(9,09 \%)$ & $8(72,72 \%)$ & $2(18,18 \%)$ \\
\hline
\end{tabular}

Fonte: Elaborado pela autora com base nos dados disponíveis no site

<http://www.tjmg.jus.br/portal-tjmg/acoes-e-programas/conciliacao-mediacao-e-

cidadania.htm\#.W0Zyh9JKiM->, acesso em 08 set. 2018. 
Revista Eletrônica de Direito Processual - REDP.

Rio de Janeiro. Ano 13. Volume 20. Número 1. Janeiro a Abril de 2019

Periódico Quadrimestral da Pós-Graduação Stricto Sensu em Direito Processual da UERJ

Patrono: José Carlos Barbosa Moreira (in mem.). ISSN 1982-7636. pp. 82-107 www.redp.uerj.br

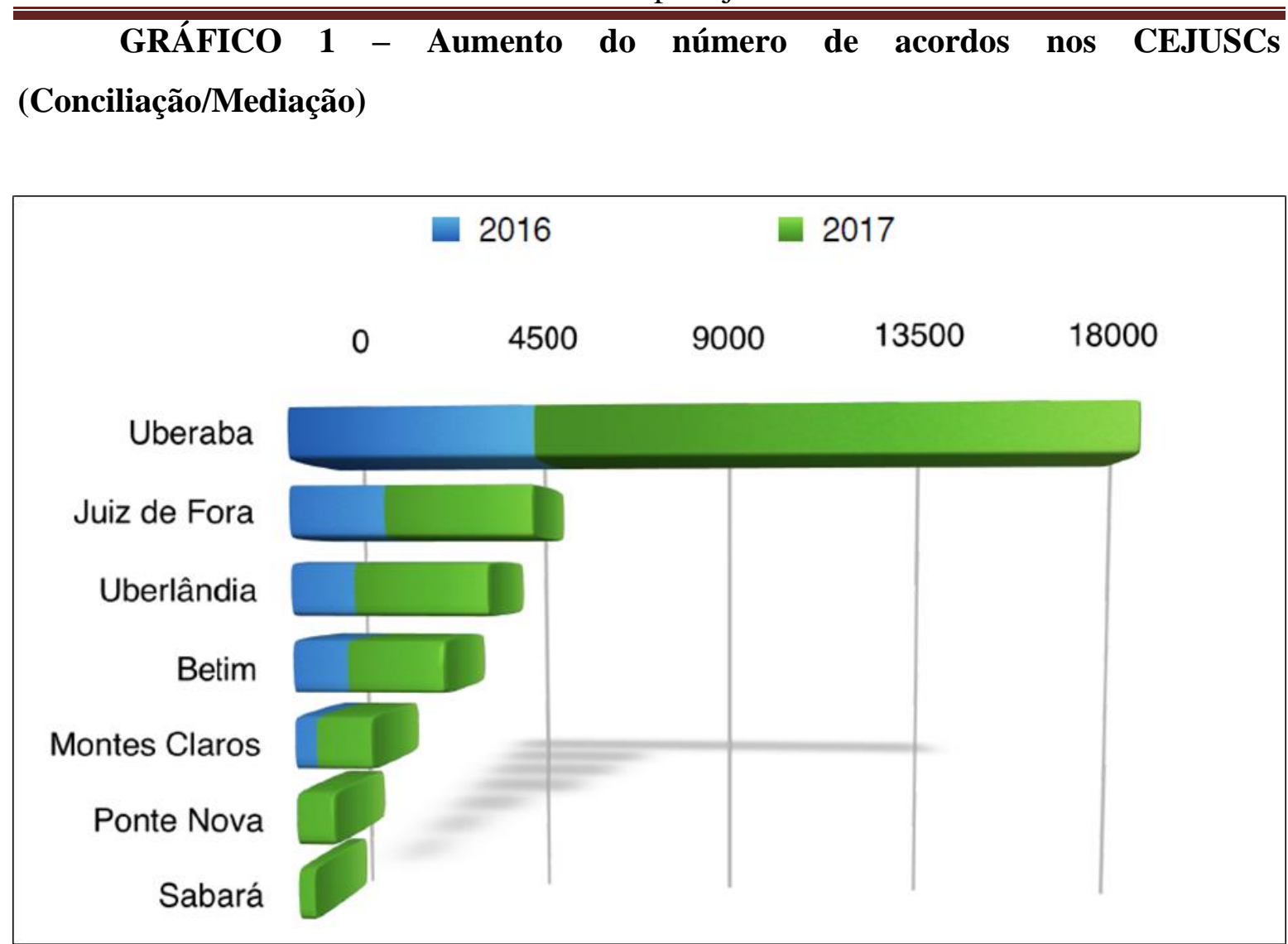

Fonte: Relatório de Atividades 2016/2018 do Tribunal de Justiça de Minas Gerais $3^{\text {a }}$ VicePresidência (2018) (não publicado)

\section{REFERÊNCIAS BIBLIOGRÁFICAS:}

ARENHART, Sérgio Cruz; MARINONI, Luiz Guilherme; MITIDIERO, Daniel. Novo Curso de Processo Civil: teoria do processo civil. 1 v. 2 ed. rev. atual. e ampl. São Paulo: Editora Revista dos Tribunais, 2016.

ARENHART, Sérgio Cruz; MARINONI, Luiz Guilherme; MITIDIERO, Daniel. Novo Código de Processo Civil comentado. São Paulo: Editora Revista dos Tribunais, 2015.

ARISTÓTELES. Ética a Nicômaco. São Paulo: Editora Atlas S. A, 2009. 
Revista Eletrônica de Direito Processual - REDP.

Rio de Janeiro. Ano 13. Volume 20. Número 1. Janeiro a Abril de 2019

Periódico Quadrimestral da Pós-Graduação Stricto Sensu em Direito Processual da UERJ

Patrono: José Carlos Barbosa Moreira (in mem.). ISSN 1982-7636. pp. 82-107 www.redp.uerj.br

AZEVEDO, André Gomma (Org.). Manual de Mediação Judicial. Brasília: Ministério da Justiça e Programa das Nações Unidas para o Desenvolvimento - PNUD, 2016.

BRASIL. Constituição da República Federativa do Brasil. In: CÉSPEDES, Lívia (Org.).

Vade Mecum Saraiva. 23 ed. atual. e ampl. São Paulo: Saraiva, 2017. p. 5- 126.

BRASIL. Lei $n^{\circ}$ 13.140/2015. Dispõe sobre a mediação entre particulares como meio de solução de controvérsias e sobre a autocomposição de conflitos no âmbito da administração pública; altera a Lei no 9.469, de 10 de julho de 1997, e o Decreto

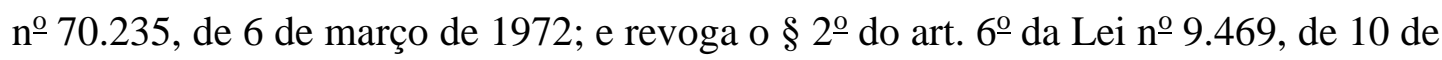
julho de 1997. Diário Oficial da União, Brasília, 29 de jun. 2015. Disponível em <http://www.planalto.gov.br/ccivil_03/_ato2015-2018/2015/Lei/L13140.htm>.

Acesso em 08 set. 2018.

BRASIL. Novo Código de Processo Civil. In: CÉSPEDES, Lívia (Org.). Vade Mecum Saraiva. 23 ed. atual. e ampl. São Paulo: Saraiva, 2017. p. 366-488.

BRASIL. Resolução nº 125 de 29/11/2010. Dispõe sobre a Política Judiciária Nacional de tratamento adequado dos conflitos de interesses no âmbito do Poder Judiciário e dá outras providências. Brasília, Conselho Nacional de Justiça, 29 de novembro de 2010. Disponível em <http://www.cnj.jus.br/busca-atos-adm?documento=2579>. Acesso em 08 set. 2018.

BUZZI, Marco Aurélio Gastaldi. et al. Guia de Conciliação e Mediação Judicial: orientação para instalação de CEJUSC. Brasília/DF: Conselho Nacional de Justiça, 2015.

CABRAL, Trícia Navarro Xavier; JÚNIOR, Hermes Zaneti (Coord.) Justiça Multiportas: mediação, conciliação, abritragem e outros meios de solução adequada para conflitos. Coleção Grandes Temas do Novo CPC, 9 v., Coordenação Geral, Fredie Didier Jr. Salvador: Juspodivm, 2016.

CAPPELLETTI, Mauro; GARTH, Bryant. Tradução de Ellen Gracie Northfleet. Acesso à Justiça. Porto Alegre: Fabris, 2002.

CORDEIRO, Carlos José; DINIZ, Priscila Aparecida Lamana Diniz. A Mediação no Direito das Famílias e a Resolução no 125/2010 do Conselho Nacional de Justiça: Perspectivas da Mediação enquanto política judiciária. In.: CORDEIRO, Carlos José; GOMES, Josiane Araújo (Coord.). 1 v. Temas contemporâneos de direito das famílias. São Paulo: Editora Pillares, 2013, p. 483-503 
Revista Eletrônica de Direito Processual - REDP.

Rio de Janeiro. Ano 13. Volume 20. Número 1. Janeiro a Abril de 2019

Periódico Quadrimestral da Pós-Graduação Stricto Sensu em Direito Processual da UERJ

Patrono: José Carlos Barbosa Moreira (in mem.). ISSN 1982-7636. pp. 82-107 www.redp.uerj.br

DIAS, Maria Berenice. Manual de Direito das Famílias. 10 ed. rev. ampl. e atual. São Paulo: Editora Revista dos Tribunais, 2015.

DONIZETTI, Elpídio. Curso didático de direito processual civil. 21 ed. rev. atual. e ampl. São Paulo: Atlas, 2018.

JÚNIOR, Humberto Theodoro. Processo Justo e Contraditório Dinâmico. Revista de Estudos Constitucionais, Hermenêutica e Teoria do Direito (RECHTD). Rio Grande do Sul. 2(1): 64-71 janeiro-junho 2010. Disponível em <http://revistas.unisinos.br/index.php/RECHTD/article/view/4776> Acesso em 14 nov. 2017.

LAKATOS, Eva Maria; MARCONI, Marina de Andrade. Fundamentos de Metodologia científica. 5. ed. São Paulo: Atlas, 2003.

LOVETT, Frank. Uma teoria da justiça, de John Rawls [recurso eletrônico]: guia de leitura; tradução: Vinicius Figueira ; revisão técnica: Maria Carolina dos Santos Rocha. - Dados eletrônicos. - Porto Alegre: Penso, 2013.

MARINONI, Luiz Guilherme; MITIDIERO, Daniel; SARLET, Ingo Wolfgang Curso de direito constitucional. 6. ed. São Paulo: Saraiva, 2017.

MINAS GERAIS. Tribunal de Justiça. Emenda Regimental no 11, de 29 de maio de 2017. Altera a redação do inciso XIV do art. $9^{\circ}$ e acrescenta o inciso VII ao art. 31, todos do Regimento Interno do Tribunal de Justiça do Estado de Minas Gerais. Diário da Justiça Eletrônico, Belo Horizonte, 30 mai. 2017. Disponível em <http://www8.tjmg.jus.br/institucional/at/pdf/er00112017.pdf>. Acesso em 08 set. 2018.

MINAS GERAIS. Tribunal de Justiça. Portaria Conjunta nº 500/PR/2016. Instala o Centro Judiciário de Solução de Conflitos e Cidadania da Comarca de Uberlândia. Diário da Justiça Eletrônico, Belo Horizonte, 16 mai. 2016. Disponível em <http://www8.tjmg.jus.br/institucional/at/pdf/pc05002016.pdf>. Acesso em 08 set. 2018.

MINAS GERAIS. Tribunal de Justiça. Portaria no 3335/PR/2016. Designa Juiz Coordenador e Juiz Coordenador Adjunto do Centro Judiciário de Solução de Conflitos e Cidadania da Comarca de Uberlândia. Diário da Justiça Eletrônico, Belo Horizonte, 16 mai. 2016. Disponível em 
Revista Eletrônica de Direito Processual - REDP.

Rio de Janeiro. Ano 13. Volume 20. Número 1. Janeiro a Abril de 2019

Periódico Quadrimestral da Pós-Graduação Stricto Sensu em Direito Processual da UERJ

Patrono: José Carlos Barbosa Moreira (in mem.). ISSN 1982-7636. pp. 82-107

www.redp.uerj.br

<http://www8.tjmg.jus.br/institucional/at/pdf/po33352016.pdf>. Acesso em 08 set. 2018.

MINAS GERAIS. Tribunal de Justiça. $3^{\text {a }}$ Vice-Presidência. Relatório de Atividades 2016/2018 (2018) (não publicado).

MINAS GERAIS. Tribunal de Justiça. Resolução nº 682 de 24 de novembro de 2011.

Dispõe sobre a instalação e o funcionamento dos Centros Judiciários de Solução de Conflitos e Cidadania nas comarcas do Estado de Minas Gerais. Diário da Justiça

Eletrônico, Belo Horizonte, 25 nov. 2011. Disponível em <http://www8.tjmg.jus.br/institucional/at/pdf/re06822011.pdf>. Acesso em 08 set. 2018.

MIRANDA, Jorge (Org.) Direitos Fundamentais: uma perspectiva de futuro. São Paulo: Editora Atlas S.A, 2013.

NADER, Paulo. Introdução ao estudo do direito. 40. ed. rev. e atual. Rio de Janeiro: Forense, 2017.

TARTUCE, Fernanda. Mediação no Novo CPC: questionamentos reflexivos. Novas

Tendências do Processo Civil: estudos sobre o projeto do novo Código de Processo Civil. Org.: CAMARGO, Luiz Henrique Volpe; FREIRE, Alexandre; JÚNIOR, Fredie Didier; MEDINA, José Miguel Garcia; DANTAS, Bruno; NUNES, Dierle; Miranda de Oliveira. 2013. Disponível em www.fernandatartuce.com.br/artigosdaprofessora. Acesso em 14 de novembro de 2017.

TARTUCE, Fernanda. Mediação nos Conflitos Civis. 3. ed. rev. atual. e ampl. Rio de Janeiro: Forense; São Paulo: MÉTODO: 2016.

TARTUCE, Flávio. Direito de Família. 5 v. 12 ed. rev. atual. e ampl. Rio de Janeiro: Forense, 2017.

THEODORO JÚNIOR, Humberto. Curso de direito processual Civil. 59 ed. atual. e ampl. Rio de Janeiro: Forense, 2018.

WATANABE, Kazuo. Acesso à Justiça e Sociedade Moderna. In: DINAMARCO, Cândido Rangel; GRINOVER, Ada Pellegrini; WATANABE, Kazuo (Coord.). Participação e Processo. RT, p. 128-135, 1988. 